\title{
Post Value Fine Management System for Power Plant
}

\author{
Aiguo $\mathrm{Li}^{1, \mathrm{a}}$, Jiaojiao $\mathrm{Du}^{2, \mathrm{~b}}$, Jing He ${ }^{3, \mathrm{c}}$, Qi Yang ${ }^{4, \mathrm{~d}}$ \\ ${ }^{1,2,3,4}$ School of Computer science and Technology, Xi'an University of Science and Technology. \\ Xi'an, 710054,China \\ ali_ag@sina.com, ${ }^{b}$ dujiao8675@126.com, ${ }^{\circ h}$ ejing_1230@163.com, \\ dsniper-yang3@sohu.com
}

Keywords: Post Value Management; Information Management System.

\begin{abstract}
At present, fine management of post value has become an important measure for enterprises to realize cost control and fine management. This paper sets forth the operating management mode of the value chain of post value system, also known as overall budget management and target cost management of the working staff. The paper formulates a post value system based on $\mathrm{B} / \mathrm{S}$ mode. The running output proves that the system possesses a prospect of wide application in view of its favorable expandability and simplicity in maintenance as well as it effectiveness in boosting the profits for gangue power plants.
\end{abstract}

\section{Introduction}

Post value fine management comes from fine management idea. The nature of this idea is a process which refines, decomposes and implements on the strategy and target and is to let the enterprises strategy planning effectively implement to each phase and play a role. To improve efficiency, the enterprises raise the concept of the fine management based on post value and extended the application of this concept into the enterprises ${ }^{[1]}$.

Post value fine management of enterprise introduce the market economy system into the enterprise to make it become a market, establish the enterprises internal market rules to make the enterprises' governing body moves from leadership to post even to employee, make every post of production process as "operators". The essential meaning is that everyone is manager and each post is profit source. The purpose of post value fine management is to encourage employees to realize increment of post, enterprises and employee. The application of post value fine management in electrical power enterprise can enhance core competitiveness of enterprise and push forward enterprises' development rapidly and well ${ }^{[2,3]}$.

It is necessary to use information platform management to realize post value fine management. Since the traditional management system based on manual work has too many shortages which restrict the development of enterprise, which will appear loss situation ${ }^{[4,5]}$.

Therefore, the development of post value fine management system is imperative for enterprise. Applying post value fine management idea in power plant, we developed the post value fine management system. By analyzing the situation of power plant, we realize their basic needs from seven aspects. They are Information recorded, User management, Workload management, Comprehensive query, Statistic analysis, Order management.

\section{System function}

There are eight modules to realize the post value fine management system for power plant. They are information management, workload management, comprehensive query, screen-display, statistic analysis, order management, materials market and user management.

(1)Information management module is mainly to manage basic information, which is not often changed is data foundation of whole system. It is operated by designated person who perform the addition, deletion and updating. 
(2)Workload management module is mainly to type-in duty information, post norm, consumptive material usage, safety inspection registration, civilization production records, workload modify about every day and every class. Counter should type-in information timely to convenient leader to view them.

(3)Comprehensive query module is mainly to inquiry post value information, duty employee information, material consumption information, post norm, safety assessment information, civilization production information in every day and every class. Considering the OA system of the company need to realize seamless butt joint, it is necessary to make form as excel. Because excel form can be easily through the company's OA system transmission and distribution.

(4) $\mathrm{OSD}$ (on screem display) module is mainly to control which screen displaying which part of information. Employees can view their value information when they are displayed on the department screen. This module is operated by counter who will need to display publicly content in the corresponding LED electronic large screen.

(5)Statistic analysis module is mainly to provide historical data to inquiry. Value information of employee, class, post, department and plant, material costs information and Post quota information, duty information, safety assessment information and civilized production information and station change information can be inquired. These historical data by the form of information directly shows diagrams to users, and the value of statistical information output by statements which is exported to excel for user-friendly these statistical analysis report.

(6)Order management is one of the characteristics of the whole system. The flow of making orders, verifying orders and checking orders reflects the whole production process and reflects all the materials circulating process. Department of issuing orders may get materials and pay money by card which improve efficient of materials supply and production efficient. Thus, enterprises and worker the win-win purpose can be achieved.

(7)Materials market management system is oriented to material market. Putting in storage, putting up warehouse operations and records query of materials are provided.

(8) The functions of user manage for administrators are provided in order to use the system to login information management and the user permissions management. It includes assign user, user limit of authority, user login validation, user operations log management and a series of those functions guarantee security of the whole system running.

\section{Software structure}

\subsection{Software system structure}

According to the operational characteristics of power plant, the post value fine management system based on B/S module was built for meet all needs of power plant. ASP.net as development tool, SQL Server 2005 as database, ADO.NET as interactive management of data and front desk page were adopted. $\mathrm{B} / \mathrm{S}$ architecture means browser/server structure.

$\mathrm{B} / \mathrm{S}$ architecture was adopted, because maintenance workload is less and it does not need to install and configure software in the client. Manager only needs to update the software to the latest version. Other client only log on system again, client could have used the latest software already. All operation happening can be known by B/S architecture on time, which is convenient to make decision quickly and avoid loss of enterprise efficient. To the software base on $\mathrm{B} / \mathrm{S}$ architecture, data is safer. 


\subsection{Software flow}

Huangling power plant includes six departments, which are the first workshop, the second workshop, fuel transport workshop, chemical water workshop, maintenance workshop and office. The first workshop and the second workshop have boiler hillock, turbine hillock and electrical hillock. Fuel transport workshop has conveying hillock. Chemical water workshop has water treatment hillock. Maintenance workshop has maintenance hillock. Water treatment hillock of chemical water workshop translate raw water to excepted salt water then transport to boiler hillock of the first workshop and the second workshop. Fuel translate hillock of fuel transport workshop transport the coal to boiler of the first workshop and the second workshop. The boiler hillock of the first workshop and the second workshop translate the excepted salt water and coal to vapor and transport to turbine hillock. The turbine hillock translate gas to electricity and transport to electrical hillock who make the electricity into internet electrical power. If the machines of the first workshop, the second workshop, fuel transport workshop and chemical water workshop have some wrong, they can make orders to maintenance hillock of maintenance workshop will check orders and repair machine. The flow diagram is as follow:

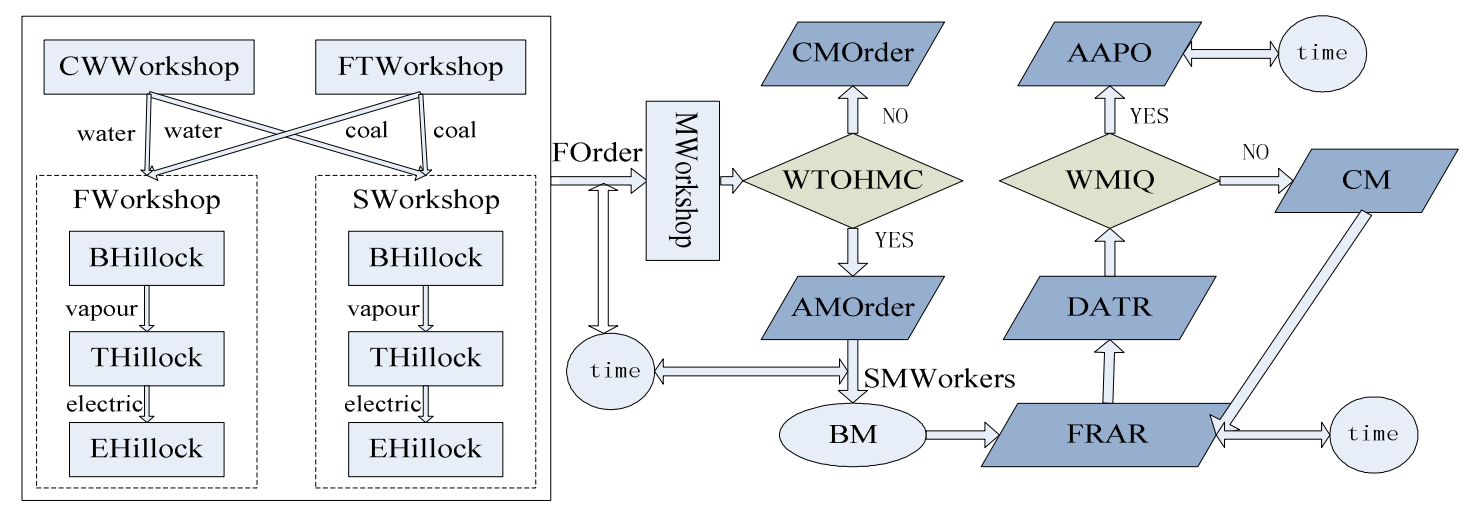

Figure 2. Gangue power plant production processes

Abbreviations of content of figure 2 are in table 1.

Table 1. Abbreviations of department and operations in figure 2

\begin{tabular}{|l|l|l|l|}
\hline Full name (department) & Abbreviation & Full name (operations) & Abbreviation \\
\hline First Workshop & FWorkshop & Acknowledge maintenance order & AMOrder \\
\hline Second Workshop & SWorkshop & $\begin{array}{l}\text { Whether the order has } \\
\text { maintenance conditions }\end{array}$ & WTOHMC \\
\hline Fuel Transport Workshop & FTWorkshop & Whether maintenance is qualified & WMIQ \\
\hline Chemical Water Workshop & CWWorkshop & Begin maintenance & BM \\
\hline Maintenance Workshop & MWorkshop & Fill in reports After repaired & FRAR \\
\hline Boiler Hillock & BHillock & Department accept the report & DATR \\
\hline Turbine Hillock & THillock & Accept and pay orders & AAPO \\
\hline Electrical Hillock & EHillock & Continued maintenance & CM \\
\hline Send Maintenance Workers & SMWorkers & Formulate orders & FOrder \\
\hline & & Cancel maintenance order & CMOrder \\
\hline
\end{tabular}

\section{Key Technologies}

This system software was developed by adopting modeling thoughts and using Microsoft Visio to draw UML diagram. UML is composed by diagram and meta-model. Diagram is grammar of UML, while meta-module give the meaning of diagram which is semantics of diagram. 
UML throughout the entire process of whole system development, use case diagram and class diagram which are used in system function requirement analysis phase are useful for system modeling. Use case diagram describe system function from the user viewpoint, express users demand. Through the use-case modeling, external role and function of the system their need can be module, customers' requirements can be specified by each case.

Under the order management face the maintenance workshop of the module. Software modeling practical implementation process was illustrated. Use case diagram and sequence diagram of order management were adopted to illustrate the implementation process of order management. The software modeling process is as follows:

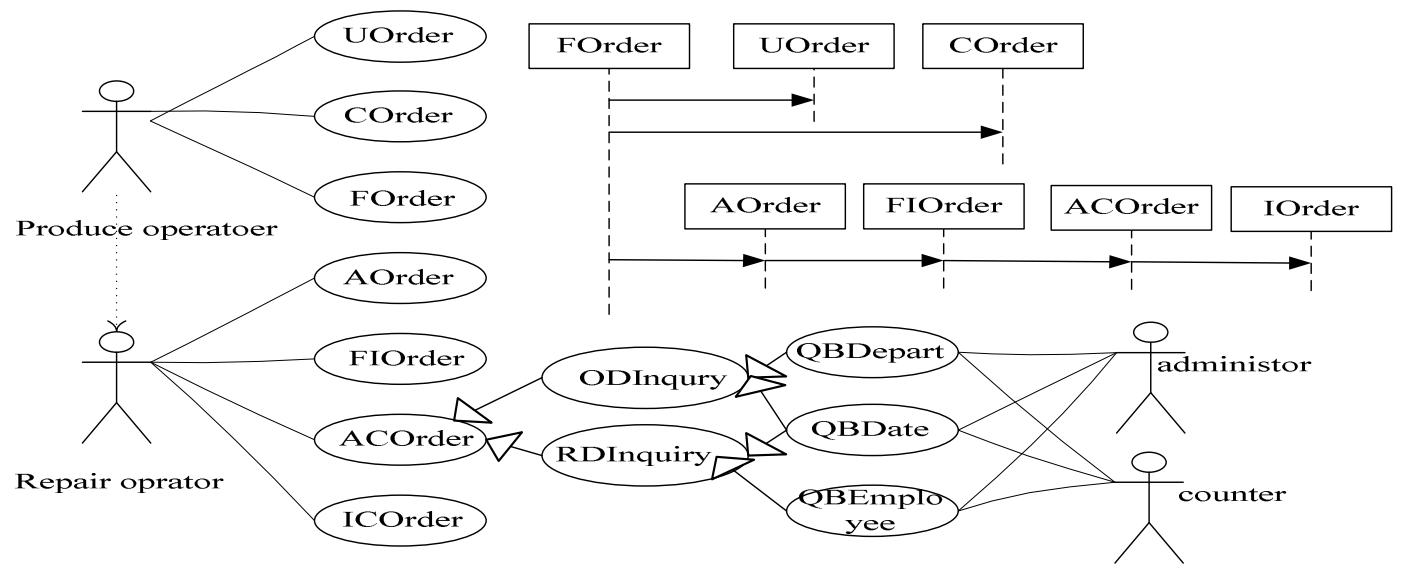

Figure 3. Use case diagram and sequence diagram of maintenance order management Abbreviations of content of figure 2 are in table 1.

Table 2. Abbreviations of use case in figure 3

\begin{tabular}{|l|l|l|l|}
\hline Full name & Abbreviation & Full name & Abbreviation \\
\hline Update orders & UOrder & Order department inquiry & ODInquiry \\
\hline Cancel orders & COrder & Repair department inquiry & RDInquiry \\
\hline Formulate orders & FOrder & Inquiry by department & IBDepart \\
\hline Acknowledge orders & AOrder & Inquiry by date & IBDate \\
\hline Fill in reports & FIReport & Inquiry by employee & IBEmployee \\
\hline Accept orders & ATOrder & Inquiry orders & IOrders \\
\hline Input card number & ICNumber & & \\
\hline
\end{tabular}

\section{Conclusion}

A post value fine management system was developed which is an important way to realize enterprises cost control and fine management. Fine management idea is an important technique support to realize the system. Asp.net, ado.net and SQL Server 2005 technology are adopted to complete post value fine management system based on $\mathrm{B} / \mathrm{S}$ model .This system meet the basic needs of enterprises post value which has good scalability, maintainability, friendly interface, the simple operations and practicability. This system has friendly interface, the operation is simple, practical, etc. This system has been applied in huangling mining group's coal gangue power plant and it is running well, which reduced the cost, and has brought many benefits to power plant. At the same time it has good reference to other enterprise post value management. 


\section{References}

[1] what is fine management.http://www.sdhsg.com/main/subject/subject_page.jsp? $\mathrm{id}=244 \& \mathrm{f}$ id $=21$.

[2] jianguang kang.Application of Fine Management of post value in coal enterprises [J].china coal industry.2008-9.

[3] Liao Zuwei, Zhang Yi, Rong Gang, Yang Yongrong. Improving Refinery Profits via Fine Management of Hydrogen Networks[J].china petroleum processing and petrochemical technology.2010-2.

[4] Pudjianto, Ramsay, Strbac. Virtual power plant and system integration of distribut- ed energy resources[J]. Institution of Engineering and Technology.2007-4.

[5] Virupax M. Nerlikar. Information management and security system[J],united states parent.1997-5. 